\title{
Ensinando História: distâncias entre teorias e práticas
}

Igor Henrique Lopes de Queiroz*

Resumo: $\mathrm{O}$ presente trabalho relata a experiência de estágio supervisionado em História (UDESC), em uma quarta série (quinto ano) da E.E.B. Simão Hess, em Florianópolis. Percebemos, em observação, que o material utilizado em sala para o ensino da disciplina reproduzia preconceitos a respeito de indígenas, africanas/os e afrodescendentes, sob a condição de escravidão, no período colonial brasileiro. Utilizando referenciais teóricos da Didática da História, investigamos as ideias das crianças sobre a temática e, a partir de textos, imagens e brincadeiras, estimulamos as crianças a construírem outras histórias e representações sobre o tema.

Palavras-chave: Estágio; Ensino; História; Preconceito.

Abstract: This paper reports the experience of supervised training in History (UDESC) in a fourth grade (fifth year) of E.E.B. Simão Hess, in Florianopolis. We realized, in observing that the material used in the classroom for teaching the discipline reproduced prejudices about indigenous, africans and african descents under the condition of slavery in colonial Brazil.Using theoretical references of history didactics, we investigated children's ideas on the

* Mestrando do Programa de Pós-Graduação em História da Universidade Federal de Santa Catarina. Bolsista CNPq. E-mail: igorhlqueiroz@gmail.com. 
subject, and from texts, pictures and games, encouraged the children to build stories and other representations on this issue.

Keywords: Training; Education; History; Prejudice.

\section{Introdução}

Aprendemos cotidianamente sobre a importância e a necessidade de se pensar em realidades culturais e identitárias múltiplas, contribuindo para o respeito às diferenças, estejam elas relacionadas às discussões étnico-raciais ou ao gênero. Autores como Silva e Fonseca (2007, p. 64), por exemplo, apontam para a necessidade de "[...] construção de uma proposta curricular temática e multiculturalmente orientada, de uma perspectiva crítica e transformadora". A Lei brasileira 10.639/2003, posteriormente complementada pela Lei 11.645/2008, atende a parte destes anseios, ao colocar a obrigatoriedade do ensino nas escolas sobre as temáticas de História e Cultura afro-brasileira e indígena, ${ }^{1}$ contribuindo para a luta contra os estereótipos, os preconceitos e, consequentemente, o racismo e a exclusão. Infelizmente, apesar de quase uma década já ter se passado desde que a primeira Lei foi sancionada, ${ }^{2}$ constatamos que as realidades vivenciadas dentro do ambiente escolar ainda podem estar absurda e assustadoramente distantes das teorias multiculturais que estudamos nos bancos universitários: esta foi a principal conclusão a que chegamos durante o estágio curricular obrigatório.

Nossa prática de docência teve lugar na Escola de Educação Básica Simão Hess, no bairro Trindade, cidade de Florianópolis,

1 Lei 11.645, de 10 de março de 2008. Presidência da República. Disponível em: <http://www.planalto.gov.br/ccivil_03/_Ato2007-2010/2008/Lei/L11645.htm >. Acesso em: 01 set. 2011.

2 O presente texto foi desenvolvido no segundo semestre de 2010, sete anos após a implementação da Lei 10.639/2003. 
capital do Estado de Santa Catarina. O primeiro contato seria apenas de observação de alunas e alunos de uma turma de quarta série (quinto ano). Deveríamos perceber seus comportamentos em sala, como lidavam com os conteúdos ministrados e quais seriam as principais dificuldades das crianças. Pudemos perceber a natural falta de comportamento das crianças, o que chamaremos aqui simplesmente de típica euforia infantil, que as fazia conversar em voz alta, mesmo sentados em lados opostos da sala, além de constatarmos que a turma se dividia em pequenos grupos um pouco hostis entre si e que algumas alunas e alunos, em geral afrodescendentes, não se encaixavam dentro dos mesmos.

A turma em questão era comandada por duas professoras, pedagogas por formação. A professora que ministrava a disciplina de História para as crianças estava ausente nesse primeiro contato que tivemos. Descobrimos, em conversa com a professora regente, que a escola em questão não possuía material didático específico para ensinar a disciplina, sendo a mesma ministrada mediante textos aleatoriamente escolhidos por essa professora ausente. Soubemos por sua colega de sala que o conteúdo ministrado seria de História do Brasil, mais especificamente sobre o período colonial. Qual não foi nossa surpresa ao ler o material escrito no quadro, que havia sido deixado pela professora ausente. Intitulado O caminho do Ouro, o texto discorria sobre o estímulo do ouro para a economia do período, sua venda e troca por mercadorias, as dificuldades iniciais em encontrá-lo e as adversidades vivenciadas pelos "heroicos" colonos. Quase ao final do texto e sem nenhuma menção anterior ao sistema escravista brasileiro ou qualquer referência ao que significava trabalhar limitado à degradante condição jurídica de escravo, lemos a seguinte frase: "Ainda tinha os negros e os indios que escondiam dos patrôes quando catavam grandes quantidades de ouro, vendiam ou trocavam por mercadorias" (grifo nosso).

Questionada sobre a possibilidade de modificar a frase que grifamos acima, visto que identificamos que a gravidade de tal enunciação poderia ser diminuída se, por exemplo, a palavra 
"patrôes" fosse suprimida ou trocada por outra mais academicamente próxima dos fatos históricos, como "senhores". As falas da professora foram emblemáticas para constatarmos o quão distante as aulas ministradas por tais professoras da escola estão das tão bem formuladas teorias que aprendemos e reproduzimos no âmbito da academia: "O texto é bem antigo. Eu cheguei e já estava assim. Não vou me indispor com as pessoas”. O exercício proposto às crianças após a leitura do texto, uma atividade para marcar verdadeiro ou falso, tinha como um dos itens "[...] os índios e negros não enganavam seus senhores [...]” e, de acordo com o que haviam lido, as crianças responderam automaticamente que era falso. Apesar da mudança da palavra "patrão" para "senhores", durante o exercício, os danos já estavam internalizados - assistimos a um exemplo de como uma simples frase pode contribuir para a reprodução de preconceitos, estereótipos e, mais especificamente, racismo.

Culpar outrem por um erro que cometemos talvez seja a medida mais fácil em um momento de tensão. Esta foi a escolha feita pela professora em questão, que preferiu apontar a culpa da escolha de tal texto para a professora ausente e decidiu por não apagar uma simples frase do quadro nem ao menos modificar uma palavra dela, não se dando nem ao trabalho de explicar que relaçôes econômicas e de poder estavam postas em tal conjuntura da História do Brasil colonial - postura esta que contraria abertamente os objetivos gerais encontrados nos Parâmetros Curriculares Nacionais para o Ensino Fundamental, que determinam, entre outras coisas, que o ensino deve

[...] conhecer e valorizar a pluralidade do patrimônio sociocultural brasileiro, bem como aspectos socioculturais de outros povos e nações, posicionando-se contra qualquer discriminação baseada em diferenças culturais, de classe social, de crenças, de sexo, de etnia ou outras características individuais e sociais [...] (BRASIL, 1997, p. 05)

Quanto ao ensino de História, mais especificamente, os Parâmetros determinam a articulação de conteúdos com temas transversais que busquem explicar 
[...] as relações de trabalho existentes entre os indivíduos e as classes, por meio do conhecimento sobre como se processam as produçôes, as comercializações e a distribuição de bens, as desigualdades sociais, as transformaçốes das técnicas e das tecnologias e a apropriação ou a desapropriação dos meios de produção pelos trabalhadores [...] as diferenças culturais, étnicas, de idade, religião, costumes, gêneros, sistemas econômicos e políticos [...] (BRASIL, op. cit., p. 31)

O texto escolhido para ministrar tal conteúdo, portanto, assim como a recusa da professora em modificá-lo ou ao menos explicá-lo, além de transmitirem conhecimentos parciais, preconceituosos e incompletos, opõem-se abertamente aos Parâmetros estabelecidos pelo MEC.

Que consequência tal ato pode ter? Que influências textos como o utilizado pelas professoras podem ter na formação de crianças de uma quarta série? Que tipo de representação ${ }^{3}$ sobre indígenas, africanas/os e afrodescendentes tal texto passou para as crianças? Se, como aponta-nos Schmitd (2009, p. 39), devemos nos preocupar em orientar o ensino de História baseados em princípios como liberdade, democracia e direitos humanos, fundamentos para a formação da cidadania, que espécie de aprendizagem estaria sendo transmitida neste texto incompleto, incorreto, explicitamente preconceituoso e que contraria abertamente os Parâmetros Curriculares Nacionais?

\section{As oficinas: possibilitando outros olhares sobre indígenas, africanos e africanas}

Certamente, não poderíamos responder a tais perguntas sem um tempo maior de observação da turma. Tais questionamentos,

3 Utilizamos aqui o termo representação segundo a definição de Chartier (1991), que afirma que não há prática ou estrutura que não seja produzida pelas representações, meio pelo qual indivíduos e grupos dão sentido ao mundo e que são ao mesmo tempo práticas construtoras do próprio mundo social e de identidades sociais - resultados diretos de uma relação de força entre estas representações - além de estratégias simbólicas de poder e dominação que determinam posiçôes e relações que constroem para cada grupo. 
entretanto, foram essenciais para decidirmos quais seriam os objetivos centrais das oficinas que desenvolveríamos nos próximos encontros. Baseados na explícita exclusão e no preconceito gerado pelo texto escolhido pela professora para trabalhar a questão do ouro no Brasil colonial, portanto, decidimos realizar nossas oficinas utilizando como temas indígenas, africanos e afrodescendentes no Brasil, realizadas em três encontros diferentes.

No primeiro dia de oficina, dividimos a classe em seis grupos, de acordo com suas afinidades e relações de amizade. Distribuímos, então, textos sobre indígenas que discorriam sobre "os índios do Brasil, a sociedade indígena na época da chegada dos portugueses, objetos e construções indígenas, a organização social dos índios, religião e educação indígena e o contato entre portugueses e indígenas". Todos os textos foram elaborados pelos estagiários a partir de dados históricos e bibliografias de referência, mas adaptados para se adequar à idade das crianças. Ao final, cada grupo apresentou para toda a sala seu fragmento de texto e respondeu a seguinte pergunta: "Será que os índios hoje vivem da mesma forma que os índios de quinhentos anos atrás?". O objetivo central era capacitar alunas e alunos a distinguirem a diversidade cultural presente no Brasil colônia a partir do distanciamento do olhar eurocêntrico, buscando destacar as principais características sociais e culturais dos grupos indígenas.

Pudemos perceber, através das respostas das crianças à pergunta, a forte valorização de uma ideia de progresso, como na resposta de um dos grupos: "Não porque eles evoluíram pelo contato dos brancos com os indígenas [...]”. A religião católica também foi colocada como a mais correta, por acreditar apenas em um deus, como na seguinte resposta: "[...] os índios aprenderam coisas novas com os portugueses. Exemplo: a usar roupas, a crer em apenas em (sic) um Deus e cumprir promessas". Tentamos problematizar tais respostas discorrendo sobre a necessidade de respeitarmos as diferenças, além de destacarmos que a liberdade religiosa é uma das características brasileiras atuais e que devemos respeitá-la. 
Ao final da atividade sobre indígenas, buscamos orientar nossas próximas intervençôes partindo dos conhecimentos das próprias crianças, de acordo com a indicação de Monteiro (2007, p. 111). Esta seria uma forma, segundo a autora, de buscar-se superar o senso comum. Pedimos, então, que as crianças escrevessem um parágrafo contendo as informações que sabiam sobre o tema da escravidão, tanto indígena quanto africana. Vários estereótipos foram reproduzidos nos textos, além de alguns erros, possivelmente decorrentes do ensino deficiente que havíamos constatado, como o uso incorreto e anacrônico da palavra patrão na seguinte resposta: "[...] Escravidão é um escravo que é escravizado por um patrão que ele manda no escravo que o escravo faz tudo que ele manda (sic)" ". A maioria das crianças enfatizou o trabalho forçado, obrigatório e sujeito ao uso da violência, além de certo maniqueísmo, como na resposta "[...] quando os brancos faziam mal aos índios e aos negros". Algumas, que resolveram ilustrar seus textos fazendo desenhos, mostraram personagens amarradas e recebendo chicotadas, com balôes de diálogo com o dizer "Ai", como percebemos nas figuras (Figuras l e 2), que reproduzimos a seguir:

Figura 1: Desenho realizado por algumas crianças para exemplificar o que era a escravidão.

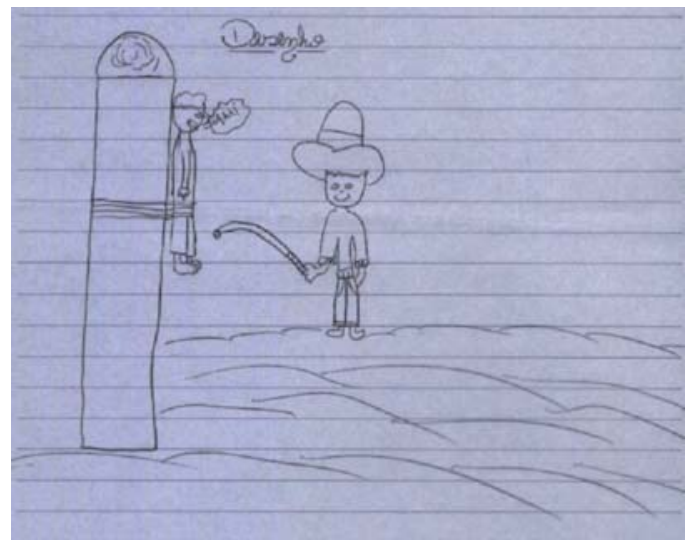

Fonte: Arquivo pessoal do autor 
Figura 2: Desenho realizado por algumas crianças para exemplificar o que era a escravidão.

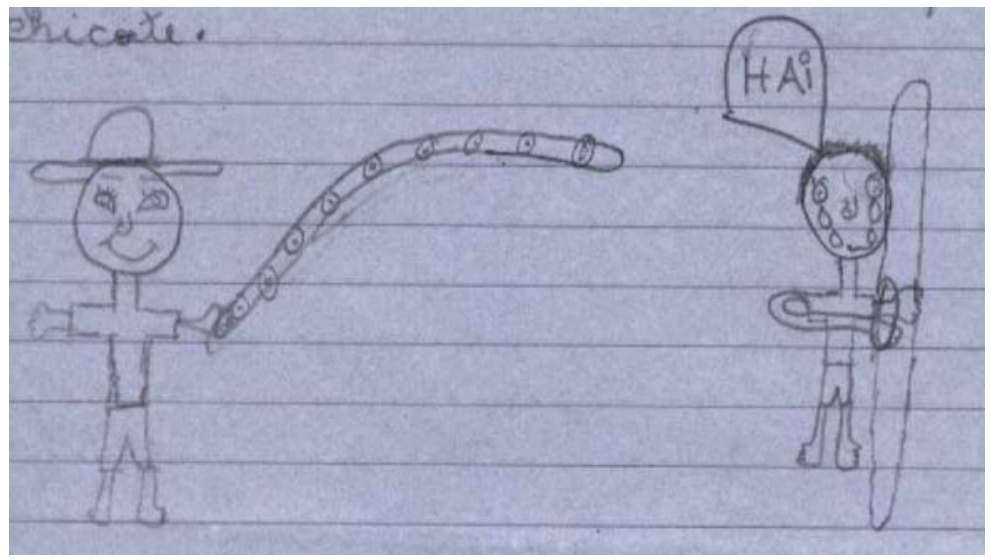

Fonte: Arquivo pessoal do autor

Tais textos e ilustrações demonstraram que as visões sobre escravidão das crianças estavam essencialmente ligadas a violências, tendo africanas/os e indígenas apenas papéis passivos e submetidos a arbitrariedades, retirando de tais personagens sua historicidade enquanto agentes sociais e culturais. Essas visões, tal qual nos alerta Cooper (2006), podem ser frutos não apenas de conhecimentos escolares deficientes, mas das múltiplas representações que acabam por construir seus conhecimentos sobre a temática, como as veiculadas pela mídia, especialmente em novelas, além de suas relações familiares e sociais como um todo.

Para nossa segunda oficina, então, outro texto foi desenvolvido. Intitulado Entre a África e o Brasil, buscamos nele retratar as principais características das sociedades africanas, suas formas de conhecimento e transmissão dos mesmos, como a tradição oral, além da abundância, riqueza e diversidade cultural presentes no continente africano. $\mathrm{O}$ texto também discorria sobre algumas características do tráfico atlântico e sobre a chegada das personagens criadas ao cenário brasileiro colonial, relatando algumas 
experiências de violência vivenciadas por tais personagens e o sistema escravista a que foram submetidas.

Ao final da leitura, dividimos a sala em grupos de forma arbitrária (nós decidimos quem trabalharia com quem, buscando evitar a exclusão de algumas crianças que percebêramos na primeira intervenção) e distribuímos imagens de Debret e Rugendas, que mostravam espaços de sociabilidades e aspectos culturais das populações africanas e afrodescendentes no Brasil colonial. Nosso objetivo central era desenvolver outro olhar acerca das populações de origem africana no Brasil colonial, explorando a presença das mesmas como essenciais para a economia, a sociedade e a cultura colonial e tentando ultrapassar a imagem estereotipada acerca dos horrores vivenciados durante o período escravista. Para atingi-lo, nossa orientação foi para que as crianças desenvolvessem a continuação das histórias das personagens que havíamos criado no texto a partir das imagens, mas sob uma condição: elas deveriam dar um final feliz às personagens.

Relações de amizade, música, dança, comércio, características alimentares, as imagens associadas ao texto desenvolvido e a nossa orientação, para que o final da história fosse positivo, permitiram às crianças que soltassem sua imaginação e ultrapassassem as visões estereotipadas acerca da presença africana e afrodescendente no Brasil colonial. Mesmo produzindo ficção, percebemos que a possibilidade de ampliar as visões acerca das populações africanas e afrodescendentes foram bastante positivas os estereótipos infantis sobre escravidão poderiam ser desconstruídos com sua própria intervenção, utilizando sua própria imaginação.

Foi interessante perceber, também, as visões sobre o que seria o final feliz para cada criança: para algumas, seria casar, ter filhos, cuidar de animais, juntar dinheiro, comprar uma casa, encontrar os pais, fazer amizade com o filho do patrão, fugir, jogar capoeira com amigos, descobrir que o irmão da história que criáramos não havia morrido na travessia atlântica, tocar 
em uma banda com amigos ou simplesmente tê-los, dentro das possibilidades que um sistema escravista proporciona para estabelecer tais laços. Algumas, inclusive, utilizaram palavras que entraram no vocabulário brasileiro bem recentemente, como no exemplo: "[...] E eles arranjaram novos amigos eles faziam a capueira e dançar e a tocar birimbal tambor corneta vuvuzela (sic) [...]". A vuvuzela, citada pelo aluno, é uma corneta utilizada por torcedores em jogos de futebol. Ficou conhecida por este nome por assim ser constantemente chamada pela mídia brasileira durante a Copa do Mundo de 2010, realizada na África do Sul.

O desfecho construído pelas crianças para cada história, portanto, dependeu do que a imagem que lhes havia sido dada retratava, mas suas histórias foram construídas a partir de seus próprios referenciais culturais e sociais, como no trecho escrito por uma aluna "[...] ele coloco (sic) suas filhas em capuera (sic) também e elas iam a aula de capuera e a Malika com seu filho ela também coloco seu filho em capuera [...]", exemplo de uma referência a situações vivenciadas atualmente por algumas crianças, que são colocadas em aulas esportivas, geralmente em estabelecimentos particulares, mas construída por meio de uma imagem que retratava o jogo de capoeira praticado por africanos e afrodescendentes.

Percebemos, entretanto, e apesar de nossas intervenções, que algumas crianças continuaram a reproduzir estereótipos, normalmente os mesmos que são constantemente veiculados pela mídia, que geralmente associam o continente africano, e consequentemente africanas/os e afrodescendentes, única e exclusivamente a imagens de pobreza, doenças, tragédias e barbarismo, imagens estas que havíamos problematizado no início de nossa intervenção enquanto errôneas. Um exemplo são os seguintes trechos, escritos por uma aluna: "[...] Os africanos moravam em um bairro muito pobre onde faziam comércio ao ar livre e mesmo assim eram felizes [...]". Mais adiante, ela fala "[...] Bokolo aprendeu a comercializar [...]". Seus referenciais, construídos a partir de imagens estereotipadas sobre o continente 
africano, portanto, fizeram com que ela continuasse a associar pobreza e ausência ou desconhecimento de comércio a africanas/ os e afrodescendentes.

Parte de nosso intento em combater uma visão única, estereotipada e preconceituosa sobre populações indígenas, africanas e afrodescendentes, apesar de não termos atingido como gostaríamos a totalidade das crianças, havia sido alcançado por meio da intervenção das próprias alunas e alunos, utilizando sua imaginação, conforme orientação de Cooper (op. cit.) para que as crianças consigam pensar de maneira histórica, visando a atingir objetivos de aprendizagem específicos. Cabia-nos, agora, descobrir os resultados de tais intervenções. Para tanto, decidimos realizar uma brincadeira de perguntas e respostas como terceira oficina, na qual revisaríamos tudo o que fora aprendido até então.

Trinta perguntas foram formuladas, todas relacionadas aos textos e às explicações que havíamos trabalhado em sala. $\mathrm{O}$ jogo desenvolvido seguiu o modelo de passa ou repassa - se um grupo não soubesse a resposta correta, passaria a vez ao outro grupo. O clima de competição e o desafio de vencer criado entre as crianças estimularam até mesmo os menos interessados em participar ativamente e dar sua contribuição para o êxito do grupo no qual estavam inseridos: aqueles que não recorriam aos textos que havíamos distribuído sobre indígenas, por exemplo, ficavam eufóricos com a contagem do tempo para que o direito à resposta passasse para seu grupo.

Ao final da brincadeira, distribuímos chocolates para toda a turma, fossem as crianças as vencedoras ou perdedoras do jogo proposto, uma forma de apaziguar os exaltados ânimos e demonstrar que, ao final, todos ganharam, por terem adquirido conhecimentos diversos àqueles que presenciáramos em nosso primeiro contato. Decidimos, também, realizar o sorteio de uma barra de chocolate entre todas as crianças e, para nossa surpresa, a sorteada foi uma das alunas mais caladas e pouco participativas de todas: uma das poucas alunas que presenciáramos ser sumariamente excluída das discussões propostas durante nossa 
primeira oficina. Atentemos ao fato de ser ela uma das poucas alunas afrodescendentes da sala. Feliz coincidência ter sido ela a sorteada? Talvez. O fato é que a autoestima de tal aluna, ao final de nossas intervenções, talvez tenha sido reelaborada e, quem sabe, até tenha melhorado um pouco, já que percebemos que sua participação nas atividades propostas aumentou consideravelmente, chegando ela a responder para seu grupo uma das questóes do jogo proposto, apesar de sua voz baixa e sua evidente timidez.

O fato é que, para além dos resultados obtidos em um curto espaço de tempo e a partir de oficinas elaboradas como uma simples experiência de docência, a constatação a que chegamos sobre a imensa distância a ser superada entre as teorias acadêmicas e a prática escolar é, no mínimo, preocupante. Formação de professores, elaboração de materiais didáticos, maior controle sobre o que é transmitido em sala de aula, reuniões periódicas sobre os conteúdos ministrados, quem poderia dizer que tais atos já não são constantemente praticados?

\section{Considerações finais}

Apesar de tudo o que é discutido e feito no âmbito da academia, ainda somos surpreendidos por situações como esta. Falta de material didático, uso de materiais absolutamente inadequados, despreocupação sobre que tipo de representação está sendo ensinada a alunas e alunos, divulgação de informações incorretas, tudo contribuindo para formar exatamente aquilo que somos ensinados a combater: o racismo e o preconceito.

Nas palavras de Bergmann (1989/1990, p.36-37)

[...] o ensino de História elabora e transmite conhecimentos e percepções, contribuindo $[\ldots]$ para a formação de convicções que permitem ao aluno uma orientação na sua respectiva sociedade $[\ldots]$ produz e transmite $[\ldots]$ orientaçóes e atitudes pelas quais um pensamento histórico racionalmente elaborado, de acordo com a auto-identidade, cria condiçôes reais para a práxis individual e social [...]. 
O ensino da História, portanto, não pode ser visto como o estudo de um passado remoto, utilizando, para desenvolvê-lo, textos inapropriados, como se o que é dito não tivesse ligação alguma com a realidade atual, tal qual presenciamos em nosso primeiro dia em sala de aula. Ele é essencial para o estabeleci mento de relações individuais e sociais positivas e inseparavelmente ligadas ao tempo presente: atualmente estereótipos e preconceitos, ao serem ensinados e reproduzidos, podem causar danos por vezes irreparáveis e atitudes excludentes e violentas, por mais que pareça, aos olhares menos atentos, tratar-se apenas de algo, como a escravidão, que aconteceu num remoto passado, mas não faz mais parte da sociedade. A pergunta que nos ocorre é: mas será que não faz mesmo? Quais seriam as razões, então, de termos observado maiores dificuldades de relacionamento, pouco interesse e menor participação justamente entre as crianças afrodescendentes? Seria muita pretensão tentarmos responder tal pergunta sem conhecermos suas trajetórias, suas relaçôes familiares, seus problemas e as dificuldades específicas que enfrentam, mas a inquietante pergunta não pode deixar de ser feita: será que estas crianças estão realmente tão distantes das violências da escravidão e do verdadeiro Apartheid social, cultural e econômico enfrentado pela maioria da população afrodescendente do Brasil?

Devemos trabalhar o ensino de História atentas/os para a formação do que Rusen (2006) chama de consciência histórica, através da qual as crianças interpretam o passado como História e atribuem sentidos às experiências temporais. Tal consciência será fundamental para entender o presente, pois é através dela que se estabelecerão usos e funções para a História, tanto na vida privada quanto na pública, formando subjetividades e permitindo conhecer a historicidade de si e do grupo em que se está inserido. A formação da consciência histórica, portanto, é essencial tanto para a socialização quanto para a individualização de tais sujeitos, tendo reflexo direto na vida prática, no cotidiano.

Um caso específico, de uma turma específica, de uma escola específica. Este poderia ser o argumento utilizado aos 
que defendem estarmos vivendo tempos outros dentro das instituiçôes educacionais brasileiras. Outras perguntas, então, imediatamente nos surgem: será um caso tão específico assim? Ou estaria tal situação ocorrendo em outros locais? É impossível responder tais questionamentos em um simples ensaio de prática docente. Atentemos, entretanto, que uma sala de aula de trinta alunos não é pura e simplesmente um caso específico. São trinta pessoas, trinta sujeitos, trinta identidades que se formarão e que sofrerão influência direta daquilo que lhes é ensinado, dos valores que aprendem e que carregarão para a vida. Se considerarmos que todas possuirão uma rede de sociabilidades que envolverá pessoas das mais diversas cores, matizes, credos, orientações, culturas, enfim, que terão contato com a multiplicidade e o multiculturalismo presente no mundo, que devem ser valorizados e, principalmente, respeitados, percebemos que trinta é um grande, um enorme número e que nossas preocupaçôes e intervenções foram mais do que válidas, elas foram necessárias. Torçamos para que tenham feito alguma diferença na formação daquelas trinta pequenas pessoas.

\section{Referências}

BERGMANN, Klaus. A história na reflexão didática. Revista Brasileira de História, São Paulo, v. 9, n. 19, set./fev. 1989/1990.

BRASIL. Secretaria de Educação Fundamental. Parâmetros Curriculares Nacionais: história, geografia/Secretaria de Educação Fundamental. Brasília: MEC/SEF, 1997. Disponível em: <http://portal.mec.gov.br/seb/arquivos/pdf/livro051.pdf $>$. Acesso em: 25 nov. 2010.

CHARTIER, Roger. O mundo como representação. Revista Estudos Avançados, São Paulo, v. 5, n. 11, p. 173-191, jan./abr., 1991.

COOPER, Hilary. Aprendendo e ensinando sobre o passado a crianças de três a oito anos. Educar. Curitiba: Ed. especial, 2006. 
MONTEIRO, Ana Maria. Os saberes que ensinam: o saber escolar. In: . Professores de história: entre saberes e práticas. Rio de Janeiro: Mauad X, 2007.

PRESIDÊNCIA DA REPÚBLICA. Disponível em: < http://www.planalto.gov.br/ccivil_03/_Ato2007-2010/2008/Lei/L11645.htm >. Acesso em: 01 set. 2011.

RUSEN, Jorn. Didática da história: passado, presente e perspectivas a partir do caso alemão. Práxis Educativa. Ponta Grossa v. 1, n. 2, p. 07-16, jul./dez., 2006.

SILVA, Marcos; FONSECA, Selva Guimarães. Ensinar história no século XXI: em busca do tempo estendido. Campinas: Papirus, 2007.

SCHMITD, Maria Auxiliadora Moreira dos Santos. Cognição histórica situada: que aprendizagem histórica é essa? In: BARCA, Isabel; SCHMITD, Maria Auxiliadora Moreira dos Santos (Orgs.). Aprender história: perspectivas da educação histórica. Ijuí: Ed. Unijuí, 2009. 